\title{
Justicia social, reconocimiento y solidaridad. Sobre la actualidad de la pedagogía de Paulo Freire
}

Fecha de recepción: 27 de febrero de 2020.

Fecha de aceptación: 29 de abril de 2020.

\begin{abstract}
Resumen
El artículo se propone revisar y ponderar la actualidad de la pedagogía freireana a la luz de los debates actuales en torno a la justicia social, tratando de identificar aquello que podría leerse como una producción original al debate, anclado en la historicidad de América Latina. De modo especial, se rescata la noción de solidaridad como condición que enlaza el reconocimiento de situaciones de injusticia con la promoción activa y las luchas por la justicia social. Finalmente, se esbozan algunas reflexiones sobre la actualidad y prospectiva que esta perspectiva abre para pensar hoy la relación entre justicia social y educación.
\end{abstract}

Palabras clave: justicia social; reconocimiento; solidaridad; pedagogía, Paulo Freire.

Social justice, recognition and solidarity. On the relevance of Freirean pedagogy

\begin{abstract}
The article aims to review the relevance of Freirean pedagogy in the light of the current debates on social justice. It try to identify what could be an original production of the debate, anchored in the historicity of Latin America. In a special way, the notion of solidarity is rescued as a condition that links the recognition of situations of injustice, with active promotion and struggles for social justice. Finally, it outlines some reflections on how this perspective contributes to thinking about the relationship between social justice and education today.
\end{abstract}

Keywords: Social justice, Recognition, Solidarity, Pedagogy, Paulo Freire. 


\section{Introducción}

La justicia social es, de modo creciente, un tema de debate en el campo de las ciencias de la educación. Desde sus inicios, en diálogo con una amplia tradición de la sociología y la filosofía crítica, pero tensionada además con investigaciones empíricas que mostraban nuevas formas de desigualdad y segmentación socioeducativa, la justicia social adoptó modos de intervención teórico-políticos diversos. Estos abarcaron desde el principio normativo para ponderar políticas públicas de inclusión y reconocimiento de identidad, a la estrategia de intervención pedagógica curricular equitativa bajo la órbita de la justicia educativa, por nombrar algunos de los puntos destacados del espectro de problematización de la cuestión.

El carácter profundamente desigual y excluyente del capitalismo, que adopta en nuestra región matices singulares por las formas violentas de opresión política, económica, cultural y de género, hace que las democracias tengan profundas deudas en torno a principios básicos de justicia social, igualdad y libertad; sobre estos cimientos la comunidad construye las formas de legalidad y legitimidad como ejercicio de autodeterminación soberana.

En este escenario, las tradiciones de la teoría social crítica han intervenido de modo constante y prolífico, produciendo textos que rápidamente se tornaron clásicos en el tema. Entre aquellos que delinearon una suerte de andamiaje teórico, se encuentra el debate sobre la redistribución y el reconocimiento, ${ }^{1}$ y los que entablan representantes de la teoría crítica, el pragmatismo, el liberalismo, el multiculturalismo de la identidad y el feminismo. Las reivindicaciones sobre redistribución económica y reconocimiento cultural han sido las más debatidas y revisitadas, también en Latinoamérica, donde ambas dimensiones de la justicia presentan desafíos, en lo que se refiere a su inclusión y democratización.

Sin embargo, desde hace muchos años y como modalidad inscripta en esta misma tradición, la pedagogía latinoamericana ha producido posiciones originales sobre educación y justicia social, su vinculación con las estructuras de la desigualdad y el reconocimiento de los derechos de los sectores sociales excluidos. Como ejercicio de un pensar situado que busca formas de liberación de la opresión, la pedagogía de Paulo Freire se constituye como una hermenéutica crítica y un programa de acción políticopedagógico, elaborado para, por y con los oprimidos. En función de esto, proponemos revisar y ponderar la actualidad de la pedagogía freireana a la luz de los debates actuales en torno a la justicia social, tratando de identificar aquello que podría leerse como una producción original al debate, anclado en la historicidad de América Latina.

En primer lugar, recuperando categorías y problemáticas del debate de teoría crítica sobre la justicia social, vamos a presentar algunos puntos de la pedagogía freireana que podrían vincularse al mismo. De modo especial, nos centraremos en la justificación o legitimidad del reclamo de justicia, los sujetos de la justicia y las dimensiones.

En segundo lugar, remarcamos algunos rasgos del análisis freireano que podrían leerse como un aporte original a los debates contemporáneos sobre la justicia social. Nos referimos a la noción de solidaridad como condición que enlaza el reconocimiento de situaciones de injusticia, con la promoción activa y las luchas por la justicia social.

Por último, esbozaremos algunas reflexiones sobre la actualidad y prospectiva que esta perspectiva abre para pensar hoy la relación entre educación y justicia social. 


\section{La reflexión crítica sobre justicia social y educación}

Aún con matices distintivos, en la filosofía y la teoría social contemporánea el abordaje crítico se caracteriza por promover una reformulación radical de los supuestos, materias, sujetos y procedimientos por los que se determina la justicia. Como pensar situado, algunos autores vienen denunciando una transformación profunda en la gramática de la justicia, lo que supone cuestionar el encuadre y los modos en los que se tematiza social y moralmente sobre si algo es justo o no.

Si la teoría crítica se define como una hermenéutica crítico-normativa que busca desentrañar las formas de dominación histórica y ponderar vías de emancipación, gran parte de su renovación pasa por las agendas de los movimientos sociales que denuncian nuevas formas de opresión y alienación. La teoría crítica es estricta respecto a las condiciones sociales, económicas y culturales del capitalismo que asume en esta fase el componente financiero transnacional, pero también supone formas de subjetivación neoliberal y - como lo viene denunciando el feminismo-componentes de una estructura patriarcal de raigambre profunda en las prácticas de las instituciones y representaciones sociales. ${ }^{2}$

Por esto, una de las características distintivas del enfoque es que el punto de vista crítico lo establecen las víctimas; es decir, el reclamo por la injusticia expresa un excedente de validez que opera como horizonte normativo de emancipación social. ${ }^{3}$ Esta impronta es fácilmente reconocible como uno de los postulados desde los que Paulo Freire elabora la pedagogía del oprimido, como búsqueda pedagógico-política para quienes se les ha negado la humanidad; para, por y con los oprimidos, en un camino de humanización y liberación que trasciende los polos de las relaciones de dominación. Encontramos también una profunda reflexión y determinación sobre los tópicos de la justicia social, esto es, un avance sobre el qué, el quién y el cómo para expresarlo en las clásicas preguntas ordenadoras sobre las que Fraser establece la justicia anormal. Freire tematiza extensamente sobre el sujeto de la justicia y la materia sobre la que versa la reivindicación; pero tal vez la apuesta más radical de su pedagogía del oprimido se concentre en el cómo. Allí se constata la posición de Fraser quien afirma que es el cómo la instancia decisiva y más radical, que modifica el qué y el quién de la justicia porque cuestiona el propio encuadre y la gramática o textura de la justicia. La pedagogía freireana se diferencia por ser para, desde y sobre todo con el oprimido; ese es uno de sus sellos distintivos frente a otras opciones críticas, ahí radica su radicalidad y novedad.

Desarrollaremos a continuación estos rasgos de la teoría crítica que se encuentran presentes en Freire y que nos permitirán vincularlo dialógicamente a los enfoque de críticos de la justicia social. Pero además, quisiéramos remarcar algunos puntos de su perspectiva político-pedagógica que podrían enriquecer e interpelar el debate en torno a la justicia que entabla la tradición de la teoría crítica, especialmente el que se centra en las políticas de la identidad, redistribución y reconocimiento. Buscaremos ahondar en aquello que Freire tiene de particular, de marca distintiva, para ponerlo en el centro del debate sobre el encuadre de la justicia y su vínculo con la educación.

2 En esta dirección se concentran las interpretaciones sobre la sociedad capitalista como orden social institucionalizado y modo de vida, que se expresan en fases, formas de gobernanza y regímenes de acumulación con explotación-expropiación (ver Frasery Jaeggi, 2019).

3 Para un análisis metateórico de las diferencias entre las teorías normativas de la justicia y una teoría crítica de la justicia, ver Grueso (2012) y Sembler (2018). 


\section{La negación de la justicia: el clamor del oprimido como punto de partida de la pedagogía freireana}

El tema de la justicia y su vinculación con la educación está presente en todo el recorrido de la pedagogía de Paulo Freire de dos modos complementarios. Por un lado, se encuentra una serie de reflexiones sobre la justicia y su relación con la práctica educativa, bajo la modalidad de condiciones sociohistóricas en las que la educación se desarrolla como viabilidad (humanización, liberación) o como negación y cosificación (deshumanización, opresión). Por otro lado, el tema de la justicia se manifiesta como una dimensión inherente a la educación entendida como práctica ético-política, como formación de la humanidad del hombre. Aquí, como veremos, es importante subrayar que esa noción de justicia aparece vinculada a una concepción profética de raíz judeocristiana, que no puede separarse de las categorías de denuncia, anuncio y esperanza.

Desde sus primeros escritos, Freire tematiza la opresión como la resultante de una matriz histórica, concretamente de una estructura política, social, económica y cultural que niega la humanidad del hombre reificándolo, le impide su plena realización. En este sentido, la opresión se opone siempre a la humanización como viabilidad ontológica. Esta situación histórica, que es el punto de partida de su pedagogía, es injusta para la mayoría de las clases populares a quienes se les niega la posibilidad de realizarse en aquello que hace a su propia humanidad, la libertad de definirse en el estar-siendo con otros.

Si el punto de partida es la negación de la justicia, la tarea ética y política del educador progresista será desarrollar una práctica de formación que no esté al servicio de estructuras injustas, sino que - presas de inconformismo- estas busquen articular el descontento, el sufrimiento, la negación de la humanidad en una tarea colectiva de transformación, liberadora de la situación de opresión. Como muchas veces lo ha definido, este proyecto político-pedagógico es una pedagogía del oprimido, para él, por él, pero sobre todo, hecha con él. Esta seña distintiva de su pedagogía crítica, está condensada en la praxis de una educación popular auténticamente liberadora y radicalmente democrática. La pregunta inicial, anterior a todo acto de educar, sobre la politicidad de la educación es uno de los principios distintivos y originales que ha legado al campo educativo:

Una educación que jamás es neutra, puede estar tanto al servicio de la decisión, de la transformación del mundo, de la inserción crítica en él, como al servicio de la inmovilización, de la persistencia de las estructuras injustas, de la acomodación de los seres humanos a una realidad considerada intocable. (Freire, 2012: 70)

Esta pregunta, que Freire coloca en el plano de la reflexión pedagógica, es una pregunta que hoy está presente, en cierto modo, en los debates que la filosofía política y la teoría social plantean sobre la justicia. Si pensamos en las preguntas con las que Fraser ordena la teorización de la justicia ( $c f r$. Fraser, 2008), encontramos en su pedagogía una clara centralidad en la cuestión del quién de la justicia. Pero además, en función de lo que venimos expresando, encontramos en Freire definiciones sobre el qué de la justicia, por ejemplo cuando la define como lo opuesto a la arbitrariedad, o como realización de una ética universal, humanista, la de los derechos humanos. También hay una preocupación central por el cómo, por el proceder justo en la práctica de la educación liberadora, y aquí solo nos basta pensar en la tematización que hace del diálogo, del rol del educador progresista, de la lucha política, la solidaridad, la democratización de las instituciones, por nombrar solo algunos tópicos. 
Con esto llegamos al segundo aspecto que queríamos subrayar en la forma de vincular la justicia con la educación, y es la forma en que entiende qué es educación. Como pocos pedagogos de la segunda mitad del siglo XX, Freire entiende la educación con un sentido normativo fuerte, como praxis ético-política, formación de la humanidad del hombre y práctica colectiva de la libertad.

Es esta interpretación normativa de lo educativo la que le permite, en definitiva, repensar críticamente la educación, revisarla y reconstruirla como interpelación desde un presente situado en espacio y tiempo. Colocar como hilo de la reflexión una idea de educación con un fuerte sentido ético-político, como principio regulativo con intencionalidad liberadora, permite actualizar su legado en la tensión entre la facticidad de modos de vida en los cuales se renuevan formas de desprecio y exclusión, y un sentido fuerte de lo educativo, como núcleo normativo y principio práctico-crítico. Si la noción de justicia que coloca Freire en sus escritos aún mantiene un potencial crítico emancipatorio es porque fue anclada en esa dimensión ética y política de lo educativo. Parafraseando a Fraser, si en algo es actual la Pedagogía del Oprimido es en que su encuadre sigue siendo prolífico en la búsqueda de problematizaciones, tensiones y desafíos e, incluso, a cincuenta años de su publicación, permite revisitar críticamente el propio encuadre de la pedagogía de la liberación.

Son múltiples y diversas las tradiciones en las que abreva la pedagogía freireana; en el caso de la justicia social subrayamos una fuente en particular, porque en su originalidad podrían encontrarse aportes al debate sobre la justicia social desde América Latina, al tiempo que interpela nuestra reflexión teórica y nuestras prácticas educativas. Nos proponemos demostrar cómo, en clave de pensar la justicia como una dimensión de la formación, es posible encontrar en Freire elementos que dialogan críticamente con algunos debates filosóficos y pedagógicos del presente. Nos referimos a una forma de entender la justicia que trasciende el necesario pero insuficiente enfoque de la redistribución, pero también a una forma de concebirla como solidaridad que completa - o si se quiere potencia- el enfoque del reconocimiento. Al preguntarnos por la profundidad de esa noción de justicia, vamos a rescatar la raíz teológica, específicamente la tradición del pensamiento bíblico profético que recupera dialógicamente la Teología de la Liberación. ${ }^{4}$ En este sentido, la religión ha conservado una tarea fundamental en la autocomprensión de la cultura occidental. Como lo viene expresando Habermas, entre otros autores contemporáneos, las grandes religiones universales han tenido la función de mediación socializadora, reconociéndoles su aporte en la conformación de ese potencial semántico, de "esa autocomprensión intersubjetivamente compartida que hace posible el trato humano de unos con otros" ( $c f r$. Habermas, 1990: 25). ${ }^{5}$

El concepto de justicia de la Teología de la Liberación es recuperado desde la tradición profética, por lo que condensa denuncia, anuncio y profecía. Esta misma dimensión profética es utilizada por Freire para hablar de educación, en la cual la práctica educativa se muestra también como denuncia y anuncio, como utopía y esperanza.

4 Esta amplia tradición es heredera del Concilio Vaticano Il y de los Documento de la CELAM de Puebla y Medellín, y si bien se encuentran muchos matices en su interior, tomamos como notas distintivas la opción radical por los pobres y su liberación desde una interpretación situada del Evangelio desde y para América Latina.

5 La valoración de la religión en un pensador como Habermas es extensa y asume diversos modos: desde advertir la matriz judeocristiana en las tesis de filosofía de la historia moderna, hasta recientemente tematizar sobre el papel de la religión en la esfera pública o sobre el valor de la lingüistización de lo sagrado en el mundo de la vida. 


\section{Hablar desde el sufrimiento del inocente: la justificación de la gramática crítica sobre la justicia social}

La Teología de la Liberación ha mostrado cómo la reflexión sobre la injusticia y las formas de exclusión son temas presentes en la tradición bíblica. Su clave hermenéutica distintiva es un pensar las formas del hablar de Dios de modo encarnado, inculturado. Por esto, hablar de Dios en América Latina se traduce en hablar del amor y la justicia en una realidad marcada por la pobreza y la opresión. Es una teología situada, que hace una opción preferencial por los pobres y crea un lenguaje de Dios desde el dolor del pueblo. En este sentido, Gustavo Gutiérrez afirma que "Toda Teología de la Liberación proviene del esfuerzo por dar sentido al sufrimiento humano cuando aquellos que sufren son víctimas de un opresión y explotación organizada, cuando son mutilados y tratados como seres inferiores a lo que son: personas humanas" (Gutiérrez, 1986: 19).

$\mathrm{Al}$ interpretar el Libro de Job, Gutiérrez demuestra que allí se encuentran elementos para fundamentar un lenguaje teológico para América Latina centrado en el clamor del inocente; pero, sobre todo, evidencia que el lenguaje profético es capaz de superar la lógica dominante para pensar la justicia centrada en la retribución. Sostenemos que esta gramática de la justicia centrada en la voz del oprimido puede ser leída en clave pedagógica y es Paulo Freire quien, concretamente, llega a vincular el clamor de la justicia de los oprimidos a una propuesta de educación liberadora. Presentaremos algunos elementos del análisis que hace Gustavo Gutiérrez de la noción de justicia que nos permitan, posteriormente, entender la apropiación pedagógica del mismo en la pedagogía del oprimido.

El tema central del libro es el sentido de la retribución y de la gratuidad de Dios. La tentación a la que se somete a Job revelará un elemento central del hablar profético: no hay denuncia sin anuncio, no hay justicia sin esperanza. Gutiérrez muestra cómo la doctrina de la retribución es el marco ideológico dominante que Job va a cuestionar en duros términos mostrando su insuficiencia, es decir, su injusticia.

En este camino que hace Job importa destacar algunas cuestiones: el sentido de la retribución; desde dónde Job se opone a la ideología de la retribución; el pasaje de la lectura individual al reclamo colectivo o social; la forma en que logra transformar su concepción de la justicia; la relación entre justicia y derecho; y la presencia de una pedagogía que partiendo de la opresión puede interpelar la visión de la justicia dominante, es decir, como retribución temporal.

En su recorrido - que es también pedagógico, de formación, de crisis, ruptura y emancipación de una mentalidad dominante- Job va a afirmar su fe primero con lenguaje profético y luego por medio de un lenguaje contemplativo. Para el objetivo que nos propusimos, vamos a detenernos solo en el primero. Los amigos de Job siguen el esquema simplista de la doctrina de la retribución, es una posición teológica cómoda y tranquilizadora para los que poseen bienes en este mundo, al tiempo que logra una resignación con sentido de culpa en quien carece de ellos. Esta forma de teísmo se convierte - advierte Gutiérrez - en una refinada forma de idolatría.

La teología de Job, en cambio, está atenta a lo concreto, a lo vivencial; es sufriente y esperanzada. Nunca olvida el amor gratuito y la compasión infinita de Dios. Pero en la denuncia del lenguaje de sus amigos, Job está revelando que siempre nuestro lenguaje es tributario de la situación en la que estamos; así las palabras de Job, acuñadas desde el dolor y el sufrimiento, pueden criticar una teología huérfana de experiencia vital y carente de compasión.

El protagonista del libro eleva sus quejas por los dolores y sufrimientos de los pobres de este mundo, y con ello está cambiando el parámetro de la ética, está pasando de una ética de méritos personales a otra atenta a las necesidades del prójimo. Y avanza 
- trascendiendo el sentido individual que caracteriza a la doctrina de la retribuciónhacia un plano social. Así llega a afirmar que la pobreza no es una fatalidad que llueve del cielo; es responsabilidad de los malvados; maldad provocada por unos cuantos que explotan y despojan al pobre, dice Job.

Por esto, advierte que ser justo significa atender y liberar al pobre. El lenguaje profético se expresa en este compromiso con el pobre y el concomitante rechazo de la idolatría. El sufrimiento del inocente se ve ahora bajo una nueva luz: creer en Dios es solidarizarse con el pobre, aliviar el sufrimiento injusto, es hacer justicia, es comprometerse con su liberación.

¿Qué nos enseña este lenguaje profético y, en qué aspecto es recuperado por Freire en su pedagogía? En primer lugar, si encontramos una clara opción preferencial por los pobres, no es porque su cualidad moral esté por encima de la de otros. No es una mirada romántica. La preferencia por el pobre se explica y torna urgente por el escándalo de la pobreza y de la exclusión; por vivir en una situación inhumana, su interpelación está dada por una certeza anterior que posibilita la propia interpelación, conmueve y responsabiliza: la universalidad de la condición humana y su realización digna y justa. Aquello que la Teología de la Liberación fundamenta en la gratuidad del amor divino, Freire lo justifica en una idea de humanización, en una ética centrada en la universalidad de los Derechos Humanos, en la esperanza de un mundo más justo.

Junto a la opción por el sujeto a educar, el lenguaje profético se expresa en la dialéctica de denuncia de la desigualdad y en el anuncio activo de un mundo más igualitario, que comienza a gestarse en las luchas sociales del presente. Esa tarea Freire la asoció al trabajo pedagógico y político, a la transformación intersubjetiva, a la detección y realización de lo "inédito viable", sueño y esperanza posible en la historia.

Otro rasgo presente del discurso profético es cómo se va gestando el proceso pedagógico formativo; el mismo surge de la interpelación fuerte entre la narración de la experiencia y el discurso de la legalidad y/o la normatividad establecida. Así como Job retó a la ideología dominante desde la vivencia de su experiencia como injusta, el discurso profético enseña que aun reconociendo la autoridad y respetando el orden normativo legal, la tradición nunca tiene la última palabra sobre la justicia. La justicia se construye en el diálogo interpelante entre las intuiciones normativas presentes en los estratos más profundos de la experiencia vivida por los pueblos, y la administración del derecho que hacen las instituciones sociales. El derecho positivo vigente no agota la justicia, por esto es tan importante la pregunta permanente sobre la realización de la justicia, procedimiento por excelencia de sociedades que anhelan vivir con justicia social. Freire suele recurrir a la palabra "dialecticidad" para dar cuenta de estas tensiones que se van resolviendo, de forma dinámica, en el curso de procesos históricos determinados.

Como educadores no podemos dejar de interrogarnos por nuestra propia práctica, cuando asistimos a un fuerte embate de saberes y procedimientos que tienden a sustituir el "sentido común" y a colonizar la competencia pedagógica, o cuando buscan silenciar las voces de los sujetos de la educación bajo un registro técnico, desgajado de la realidad, o subsumido en el lenguaje de la administración. La ideología de la retribución está en el Antiguo Testamento, pero su lógica sigue operando bajo una ética funcional al establecimiento del capitalismo (como Weber magistralmente lo analizó en La Ética protestante y el espíritu del capitalismo). Esa misma lógica se encuentra al acecho en una pedagogía que vuelve a hablar de mérito, esfuerzo, gestión de las emociones y responsabilidad individual. ${ }^{6}$ 
Otro elemento que se recupera del discurso profético es que, quien alza la voz, inicialmente la refiere a su propia subjetividad; pero es en el diálogo donde se descubre como autoconsciente, en una trama histórica con otros que también sufren injusticias. Frente a nuevas formas de exaltación de la individualidad, la pedagogía freireana remarca que si bien hay una dimensión de formación de la subjetividad, educarse es una tarea humana, colectiva, pública, que se realiza en la cooperación constructiva de saberes, valores y experiencias. En tiempos en que el neoliberalismo ha logrado privatizar todas las dimensiones de la subjetividad y colonizar el deseo poniéndolo al servicio de ciertas destrezas, releer a Freire es un acto de subversión frente a lo dado; es ir de modo crítico, no ingenuo, contra el fatalismo de las circunstancias que - como un nuevo determinismo biologicistapropone una educación "reducida a viabilizar lo ya determinado" (Freire, 2012: 67).

Las palabras que Freire formulara en 1996 resuenan en el presente, con renovadas formas de opresión y dominio: "si hoy, más que nunca es necesario remarcar el sentido de la esperanza en la práctica educativa" (Freire, 2012: 148), es porque "tenemos el deber de luchar contra el poder robustecido de los poderosos, pues la globalización lo fortaleció al mismo tiempo que debilitaba la flaqueza de los frágiles" (Freire, 2012: 69).

\section{Reconocimiento, justicia y solidaridad}

Según Haker el concepto de justicia que predomina hoy en la política global es el de la justicia del mercado, que excluye la solidaridad. La autora interviene en el debate sobre la teoría de la justicia y propone la solidaridad como un vínculo posible entre las teorías del liberalismo político y la crítica; en la tematización que hace del asunto encontramos cierta cercanía con algunas posiciones éticas y políticas gestadas en América Latina, de modo particular, la de Paulo Freire.

El punto de partida es constatar lo que se propone como justicia en el marco de la pobreza global, o dicho como su contracara, el estado de injusticia que afecta a la población más pobre. Las medidas de austeridad de las reformas socioeconómicas que impone el capitalismo financiero a los países más pobres, siempre diseñadas para salvar a los mercados, tienen adosado el adjetivo de "justas". Así, las sucesivas reformas del Estado, la flexibilización laboral, los proyectos de modificación de la Ley de Seguridad Social suelen estar acompañados por la necesidad de hacer justicia desde un criterio de retribución individual y meritocrático, de dudosa objetividad, pero que coloniza el sentido común.

Afirma que el sentido de justicia que subyace en las políticas económicas globales con respecto a la pobreza se define en términos económicos; se basa más en el mérito - diferente entre los individuos y grupos-, que en las necesidades básicas - las mismas para todos- que se encuentran enumeradas en la Declaración Universal de los Derechos Humanos; estas van desde las necesidades elementales para el mantenimiento de la vida digna hasta las libertades básicas, y la oportunidad de participar en los asuntos sociales y políticos. Las políticas económicas están más orientadas a la estabilidad del mercado que a la estabilidad social, dando como resultado un nuevo concepto de justicia de mercado, por encima y en contra de la justicia social. Es más, esa justicia de mercado parece ser indiferente a las consecuencias sociales de su propia dinámica. La interpretación que hace de lo justo se reduce a pensarla como posibilidad u oportunidad basada en el mérito; por esto, se aleja del horizonte de comprensión de otra forma de entender la justicia, asociada a la solidaridad.

Ahora bien, si de la mano de Gutiérrez y Freire, mostramos cómo la justicia se fundamenta críticamente en el clamor del inocente, Haker postula que esta justicia de 
mercado, cimentada en el mérito individual, tiene poco que ver con la tradición judeocristiana que busca dar respuesta al sufrimiento, pero sobre todo, que es una idea de justicia que niega el reconocimiento del individuo, de sus culturas y singularidades. $\mathrm{Al}$ olvidar el reconocimiento es incapaz de compasión, primera respuesta moral que exige transformar el sufrimiento en bienestar, la conversión de la injusticia en justicia, la exclusión en inclusión.

La tensión entre igualdad y justicia es un tópico central en los debates contemporáneos sobre la segunda. ${ }^{7}$ La autora observa que este concepto de justicia, al invocar las mismas reglas para todos, termina por encubrir y tolerar las desigualdades estructurales, económicas y sociales del mundo actual. Más que justificarse en un contrato económico, los problemas de nuestro tiempo requieren un concepto de justicia cimentado en un contrato social que sea capaz de corroborar la igualdad de todas las personas independientemente de la diversidad, pero que al mismo tiempo reconozca algunas diferencias, porque tampoco estas pueden dejar de ser reconocidas por sociedades que persiguen la justicia social.

En este punto Haker recuerda cómo la relación entre el principio normativo de la igualdad de todo individuo y la desigualdad estructural entre las personas persigue a las teorías contemporáneas de la justicia. Por eso entiende que la labor de toda teoría de la justicia consiste en concretar cómo la proposición normativa de la igualdad puede traducirse en políticas que afronten la desigualdad de hecho, sin omitir el reconocimiento del otro en su diferencia. Su posicionamiento es claro: la igualdad no excluye el reconocimiento de la diversidad, pero el problema central reside en saber cuándo el reconocimiento de la diferencia encubre la desigualdad, es decir, la injusticia. ${ }^{8}$ Un ejemplo de esto $-\mathrm{y}$ de cómo no son normativamente equivalentes los principios mencionados- es la complementariedad de los principios de igualdad y diferencia en la teoría de la justicia de Rawls. Aquí resulta instructiva la relación entre justicia y solidaridad.

Rawls formula el principio de la diferencia ("las desigualdades sociales y económicas tienen que organizarse de tal modo que contribuyan al mayor beneficio de los miembros menos favorecidos de la sociedad") como complementario del de la igualdad ("toda persona debe tener un derecho igual a la máxima libertad básica compatible con una libertad similar para los demás"). Haker sugiere que lo podría haber llamado principio de la solidaridad relacionado con la justicia, porque su objetivo es compensar las injusticias estructurales o los puntos de partida desiguales, la desigualdad de oportunidades.

En este punto el desafío crítico radica en cómo vincular justicia y solidaridad, cómo demostrar que pueden llevarse a cabo ambas. La autora propone introducir el concepto de reconocimiento, resignificado como "aceptación incondicional de todo individuo, independientemente del status social o económico, reconocimiento de uno mismo como uno entre otros". Comparte la premisa honnethiana de partir del "no reconocimiento", expresado como desprecio personal, discriminación social y negación de los derechos políticos, como motor de la lucha contra el no reconocimiento en las relaciones personales, las estructuras sociales y las instituciones políticas. Propone complementar las luchas de quienes experimentan el desprecio y el olvido de reconocimiento, con la solidaridad con quienes y entre los que sufren injusticias:

7 Ecos del mismo resuenan en la investigación educativa, donde es posible encontrar esta tensión en las producciones sobre justicia educativa, justicia curricular e igualdad de oportunidades.

8 Es importante que el campo crítico pueda profundizar estas tensiones entre igualdad y diferencia, igualdad y alteridad, igualdad y reconocimiento, especialmente cuando las mismas encubren o reproducen las múltiples formas que reviste hoy la desigualdad: socioeconómica, cultural, política, de género, etc. En este sentido, nuevamente, Freire ha mostrado cómo se pueden criticar las estructuras que producen la desigualdad social, con el reconocimiento político-pedagógico de conocimientos, experiencias y formas organizativas de los sectores populares. 
La solidaridad es la práctica de aceptar a quienes han sido avergonzados, la inclusión de quienes son socialmente excluidos y la defensa política y legal de quienes carecen de defensores. La justicia exige estas prácticas de solidaridad para identificar las prácticas en que la diversidad se apoya en la injusticia; la expresión injusticia, a través del relato de las víctimas, es una parte necesaria de proceso de negociación entre diferentes intereses, pero la solidaridad también exige el punto de vista de la justicia, para trascender el punto de vista necesariamente parcial de las políticas de la identidad en las que a menudo se basa la solidaridad. (Haker, 2014: 25)

Con la introducción de la solidaridad como complemento necesario de la justicia, especialmente en aquellas opciones donde el sujeto, el contenido y el procedimiento están referenciados en el punto de vista de las víctimas, es posible pensarlas como dimensiones que están presentes y forman el núcleo normativo de la educación liberadora. Pero también, encontramos en esta vinculación una clave interpretativa para releer la pedagogía freireana a la luz de los debates de la teoría crítica de la justicia social.

\section{Justicia social, reconocimiento y solidaridad: un reencuentro con la Pedagogía del Oprimido}

En 1992, después de haber ocupado la Secretaría de Educación del Estado de São Paulo en manos del Partido de los Trabajadores, Freire escribe Pedagogía de la Esperanza a la que define como un reencuentro con la pedagogía del oprimido. Ya en la introducción explica la necesidad de repensar críticamente los escritos de los años 60 y 70, sin dejar de subrayar la actualidad de los temas que allí fueron expuestos. En pleno auge del neoliberalismo en la región, la pedagogía de la esperanza nace de la "democratización de la desvergüenza, la falta de respeto a la cosa pública, la impunidad”. Leído desde el presente y luego de un ciclo de gobiernos progresistas, el diagnóstico permanece actual:

No será equitativo que las injusticias, los abusos, las extorsiones, las ganancias ilícitas, los tráficos de influencias, el uso del cargo para la satisfacción de intereses personales, que nada de eso por lo que con justa ira luchamos ahora en Brasil se corrija, como no será correcto que todas y todos los que fueran juzgados culpables no sean castigados severamente, aunque dentro de la ley. (Freire, 1993: 9)

En un territorio que sigue marcado por la desigualdad y la denuncia de nuevas formas de opresión, revisitar hoy los escritos de Paulo Freire es una necesidad urgente; hacerlo además, a la luz de los aprendizajes sociales que atravesó la región y que deben ser tematizados críticamente para ponderar procesos de formación, pero también para hacerlo con aquellos que no son auténticamente educativos según el educador brasileño, o expresan semiformación, en lenguaje adorniano. ${ }^{9}$ Por esto, "tal vez nunca haya sido tan necesario como lo es hoy para nosotros remarcar el sentido de la esperanza para la práctica educativa" (Freire, 1993: 148)

Si el planteo de Freire mantiene alguna vigencia es porque su encuadre sigue siendo emancipatorio. La forma en que se define lo educativo, su justificación en una opción a favor de los menos favorecidos, el sentido radicalmente crítico de la democracia como proyecto colectivo en permanente realización. Las nociones de igualdad, libertad y justicia que sostiene la educación popular, enriquecida con una visión particular de la solidaridad, la utopía y la esperanza, siguen siendo temas que interpelan las políticas

9 Utilizamos el concepto de Adorno para dar cuenta de un proceso de transmisión cultural que no estuvo anclado en la experiencia vital y, por ello, fue incapaz de transformar auténticamente la cultura o el sentido común. 
públicas, los modelos y prácticas institucionales, los vínculos y las relaciones de poder, las formas de transmisión y de producción de conocimientos. Esta vigencia, que excede lo educativo en un sentido meramente técnico y se proyecta a las prácticas políticas, culturales y pedagógicas que sostienen la dinámica de la vida social, se muestra de modo claro en el embate que sufre hoy su figura en su país natal. La cruzada que la derecha neoliberal gobernante en Brasil emprende contra Paulo Freire busca borrar un diagnóstico de profunda desigualdad social, pero también demuestra la potencia emancipatoria de su pedagogía y, en ello, la peligrosidad de su radicalidad democrática y popular.

Nuevas formas de deshumanización y cosificación se suman y otras subsisten. En el campo educativo, el discurso pedagógico centrado en la formación - como el de Freire- cede lugar a miradas gerenciales sobre la educación y la escuela. Sobre esto, el autor ya advertía en 1996 cómo la ética del mercado se apropia del discurso pedagógico. A más de veinte años, esa tendencia se impone en las políticas públicas de la región con reglas propias de esta fase del capitalismo financiero global. La meritocracia como valor educativo, la internacionalización y estandarización de la educación centrada en las competencias, las evaluaciones estandarizadas administradas por grandes empresas del negocio editorial, un mercado de asesoría, gerenciamiento pedagógico y capacitación docente, son solo algunas muestras de cómo esa ética del mercado ha penetrado en el campo educativo.

En este contexto, la pedagogía de Freire interpela desde el marco ético-político en el que se justifica la propuesta, esto es la confrontación de un proyecto cimentado en una ética de los derechos humanos, construida en la denuncia de la injusticia y en la realización de una pedagogía que actualiza - al concretarlo en la praxis de una pedagogía crítica, popular y democrática- la esperanza de que la injusticia no sea la última palabra en la historia.

Encontramos en su obra aportes significativos para el debate actual sobre la justicia. En un pasaje, llega a definirla en oposición a la arbitrariedad: "En un mundo así la gran tarea es garantizar las libertades, los derechos y los deberes, la justicia, y no respaldar la arbitrariedad de unos pocos contra la debilidad de las mayorías" (Freire, 2012: 169). Leída a la distancia, esta idea representa una profunda convicción y una intuición original, ya que la vamos a encontrar en los debates actuales de la teoría crítica. Así por ejemplo, Rainer Forst se pregunta por el significado más original y profundo de la justicia, para responder:

El concepto de justicia posee un núcleo de significado que tiene como concepto contrapuesto esencial el de la arbitrariedad: sea ya el dominio arbitrario de individuos, sea el de una parte de la comunidad, sea la aceptación de contingencias sociales que conducen a posiciones o condiciones asimétricas de la dominación y que son aceptadas como impuestas por el destino e inmodificables, sin serlo. El dominio de la arbitrariedad es el dominio de los hombres sin razones legítimas, y la lucha contra la injusticia está siempre dirigida contra estas formas de dominación. El impulso básico contra la injusticia no es primordialmente el de querer tener algo, o algo más, sino el de no querer seguir siendo dominado, acosado o ignorado en la pretensión del derecho fundamental a la justificación: esta pretensión contiene la exigencia de que no haya condiciones políticas o sociales que no puedan ser justificadas adecuadamente frente a los afectados. (Forst, 2015: 35)

Cuando recuperamos — de la mano de Haker- la noción de experiencia del no reconocimiento como hermenéutica crítica es porque allí se encontraba un cúmulo de expectativas morales que clamaban por ser reconocidas, o en lenguaje de la teoría de la justicia, que eran arbitrariamente sostenidas y por ende, no podían ser justificadas 
frente a los afectados. Cuando el pensamiento crítico contrapone lo arbitrario a lo justo, debemos recordar que siempre la exigencia de justicia es emancipadora en un sentido normativo, y supone en todo momento la conquista de mayores niveles de igualdad, libertad, democracia y reciprocidad. Por esto, la teoría crítica de la justicia demuestra que la gramática de la justicia es una cuestión política en tanto encuadre que define las condiciones de posibilidad, fija sujetos, temas y procedimientos de justicia. La politicidad de dicho encuadre trasciende los límites del sistema de derechos, es un problema ético-político que atañe a la autodeterminación democrática de las comunidades; pero es también una cuestión educativa, formativa de sentidos de justicia, en la significación que Freire da a la politicidad de la educación, en tanto núcleo de su pedagogía.

Por último, esto también nos obliga a considerar la rápida contraposición que suele hacerse entre escuela pública y educación popular. Si bien el mismo Freire se encargó de desmontar la identidad entre sistema educativo y educación bancaria, es el sentido ético-político el eje gravitacional sobre el que debemos pensar la lógica de la educación popular en la escuela pública. En sus últimos escritos, Freire no solo rescata a los sujetos populares y sus saberes, sino que se pronuncia sobre la construcción de una educación popular en el sistema público, en las condiciones de desigualdad estructural imperantes:

Les toca a los educadores y educadoras progresistas, enfrentarse al abuso de poder de los dominadores. Les toca, por último, realizar lo que es posible hoy, para que mañana se concrete lo que hoy es imposible. Les toca finalmente, basados en esos saberes, hacer educación popular, en el cuerpo de una red bajo el comando autoritario antagónico. (Freire, 1997: 111)

Hacer educación popular en la escuela pública entonces es retomar, actualizar y realizar esa direccionalidad ética y política; es hacer una escuela más justa, radicalmente democrática, que experimente la solidaridad; es visibilizar y atender las experiencias de injusticia, de ir contra toda forma de ejercicio arbitrario del poder y no tolerarlo porque, como enfáticamente nos recuerda Rainer Forst, tolerar es ofender.

La escuela es también el espacio donde se transmiten y legitiman las justificaciones del orden social vigente. Si en la opción que cada educador crítico hace está presente la pregunta por la arbitrariedad del poder, la politicidad de la educación en sentido freireano, estaremos haciendo de la escuela uno de los lugares donde experimentar la solidaridad y la justicia.

Frente a la hegemonía del neoliberalismo globalizado y de lógicas mercantiles que colonizan las políticas estatales, las instituciones y las subjetividades, cabe preguntarnos: ¿qué otra forma tendremos de reconstruir lo público de la escuela, desde un sentido radicalmente democrático, si no es mediante una opción de educación popular? 


\section{Bibliografía}

》Forst, R. (2015). Justificación y Crítica. Perspectivas de una teoría crítica de la política. Buenos Aires, Katz.

" Fraser, N. (2008). Escalas de Justicia. Barcelona, Herder.

» Fraser, N. y Honneth, A. (2006). ¿Redistribución o reconocimiento? Madrid, Morata.

» Fraser, N. y Jaeggi, R. (2019). Capitalismo. Una conversación desde la teoría crítica. Madrid, Morata.

» Freire, P. (1993). Pedagogía de la esperanza. Un reencuentro con la pedagogía del oprimido. México, Siglo XXI.

"Freire, P. (1997). Política y educación. México, Siglo XXI.

》Freire, P. (2000). Pedagogía del Oprimido. Buenos Aires, Siglo XXI.

"Freire, P. (2012). Pedagogía de la indignación. Cartas pedagógicas en un mundo revuelto. Buenos Aires, Siglo XXI.

»Grueso, D. (2012). Teoría crítica, justicia y metafilosofía. La validación de la filosofía política en Nancy Fraser y Axel Honneth. Eidos, nº 16:70-98.

» Gutiérrez, G. (1986). Hablar de Dios desde el sufrimiento del inocente. Salamanca, Ediciones Sígueme.

" Haker, H. (2014). Nueva reflexión sobre la solidaridad y la justicia. Concilium, 354, número monográfico: Vivir en la diversidad.

"Laval, Ch. (2004). La escuela no es una empresa. El ataque neoliberal a la enseñanza pública. Barcelona, Paidós Ibérica.

"Sembler, C. (2018). Injusticias y emancipación. La renovación de las bases epistemológicas de la crítica social. Cinta de Moebio, no 63: 377-390.

\section{Andrea Díaz}

Doctora en Ciencias de la Educación por la Universidad de Buenos Aires. Profesora Asociada de Filosofía de la Educación en la Universidad Nacional del Centro de la Provincia de Buenos Aires. Investigadora asociada de la Comisión de Investigaciones Científicas de la Provincia de Buenos Aires (CICPBA) y del Núcleo de Estudios Educacionales y Sociales (UNCPBA). andiaz@fch.unicen.edu.ar 
